\title{
Vocal behavior of Crested Guineafowl (Guttera edouardi) based on visual and sound playback surveys in the Umhlanga Lagoon Nature Reserve, KwaZulu-Natal province, South Africa
}

Johann H. van Niekerk

\begin{abstract}
Background: Generally speaking, playbacks were often ineffective to determine the group sizes of birds since mainly males from leks responded. This limitation has not been tested properly for flocking birds such as Crested Guineafowl (Guttera edouardi) with the view to use it as a counting method. The aims of the study reported in this paper were (1) to describe the calls of Crested Guineafowl in a social context; (2) to interpret calls in an evolutionary context; and (3) to demonstrate that playbacks can be used to locate and count Crested Guineafowl in small isolated forests.
\end{abstract}

Methods: The vocal behavior of Crested Guineafowl was observed during a survey conducted in the Umhlanga Lagoon Nature Reserve (KwaZulu-Natal, South Africa) from November 2010 to June 2012. Transect line observations and sound playback methods were used.

Results: The behavioral context and structure of calls were described. The eight calls described for Crested Guineafowl were produced mainly to unite flock members in the dense understory, where visibility was poor, and to repel intruders. When not disturbed, Crested Guineafowl were quiet and only made soft contact calls.

Conclusions: The high rate of call back and the fact that flocks invariably approach the source of the call en masse, shows that field researchers are able to assess the population size of Crested Guineafowl with sound playbacks along a transect. The value of playbacks as a conservation tool is assessed.

Keywords: Guttera edouardi, Playback, Calls, Social behavior, Flocking, Transect surveys

\section{Background}

The Crested Guineafowl (Guttera edouardi) is one of the least scientifically studied galliforms in southern Africa (Madge and McGowan 2002; Little and Crowe 2011). Published papers have concentrated on the viability of this species in forest patches of different sizes (Lawes et al. 2006), evolution (Crowe 1978), adaptive morphological variation of Crested Guineafowl and Helmeted Guineafowl (Numida meleagris) (Crowe 1979) and some diet studies (Wilson 1965; Hill 1974). Maier

\section{Correspondence: thirstland2@gmail.com}

Department of Environmental Sciences, College of Agriculture and

Environmental Sciences, University of South Africa, PO Box 392, Pretoria 0003, South Africa
(1982) analyzed the vocal characteristics of Helmeted Guineafowl in captivity, and identified six sound groups, but the vocal behavior of Crested Guineafowl has not been described.

The Hawaan Forest (35 ha) and Umhlanga Lagoon Nature Reserve (ULNR, 20 ha) at Umhlanga (Kwazulu-Natal province, South Africa) are forested enclaves between high-density human settlements and tourism facilities (e.g. hotels), and the forests are visited by thousands of tourists annually. No Crested Guineafowl populations exist south of these forests (Little and Crowe 2011). In light of alien plant invasion and the demand for residential space, basic information on the Crested Guineafowl's ecology is crucial to conserve these birds in these forests (Sutherland et al. 
2004; Rasaru 2007; Little and Crowe 2011). Crested Guineafowl live in closely knitted flocks with dominant birds initiating foraging direction (JH van Niekerk, personal observations). This is similar to Helmeted Guineafowl where males lead the flock (van Niekerk 2010a).

A basic description of sounds is important for identifying species, use in bio-acoustic monitoring with automated sound techniques and for phylogenetic studies (Sutherland et al. 2004; Brandes 2008; van Niekerk 2013). In forests where visibility is low, sound playbacks can be used to improve monitoring accuracy (e.g. population trends). Playbacks can be used for line transect or point transect surveys; this could be especially suitable for dense forests, where observation routes are often limited to clearings (Sutherland et al. 2004). However, playbacks were ineffective to determine the group sizes of birds such as the Red-crested Korhaans (Lophotis ruficrista), since mainly males from leks responded (van Niekerk 2014). This limitation has not been tested properly for flocking birds such as Crested Guineafowl with the view to use it as a counting method (Little and Crowe 2011).

Playbacks could have a negative effect on the behavior of birds, for instance by diverting them from other activities such as breeding or causing habituation (Lima and Roper 2009). The latter would introduce bias into a followup study (Harris and Haskell 2013). In order to use sound playbacks as an ethical conservation tool, it is important to assess the effect of playback on Crested Guineafowl and establish a protocol (Harris and Haskell 2013). The aims of the study reported in this paper were (1) to describe the calls of Crested Guineafowl in a social context; (2) to interpret calls in an evolutionary context; and (3) to demonstrate that playbacks can be used to locate and count Crested Guineafowl in small isolated forests.

\section{Methods}

Study area

The forest ( 7 ha) in the ULNR (20 ha) (S29.710028 E31.094438) was chosen for field work. A patch of mangrove and the Umhlanga Lagoon form the northern boundary, a high traffic volume dual-carriage tar road (width $25 \mathrm{~m}$ ) forms the western boundary that separates the Hawaan Forest and the ULNR, and there is a wetland on the eastern boundary and a hotel on the southern boundary. Rain falls mainly during summer, and the average rainfall is about $989 \mathrm{~mm}$ per annum (Mucina and Rutherford 2006). The vegetation is KwaZulu-Natal Coastal Belt with subtropical coastal forests (Mucina and Rutherford 2006). Indigenous trees include the Coastal Red Milkwood (Mimusops caffra), Climbing Raisin (Grewia caffra), Red Milkwood (M. obovata), Zulu Cherry-orange (Teclea gerrardii), Natal Fig (Ficus natalensis), White
Stinkwood (Celtis africana) and White Mangrove (Avicennia marina).

\section{Data collection}

The $460 \mathrm{~m}$-long footpath ( 2.5 $\mathrm{m}$ wide) through the centre of the ULNR forest, used daily by the public, was a convenient clearing from which playbacks and observations were conducted. This habitat mainly included the regular occurrence of old trees (primary canopy trees) of about 50-200 cm tree trunk diameter, 30-40 m apart and about 20-30 m high interspersed with immature understory trees with a tree trunk diameter of about $20-70 \mathrm{~mm}$ on relatively flat ground with patches of thick bushes under the canopy.

The footpath was traversed three or four times per month on separate days, from November 2010 to June 2012; (1) to record group sizes and general behavior and (2) to study the sounds in a social context. To prevent possible habituation, playbacks were limited to 1 day per month (Catchpole and Slater 2008). Each survey, whether playback was done or not, lasted approximately $30 \mathrm{~min}$. Playbacks (recorder) were directed at birds that were seen or heard but also at $30 \mathrm{~m}$ intervals along the transect without seeing or hearing guineafowl ("blind calling").

For the playbacks, two typical alarm calls (two exemplars) were recorded and played through a Sony ICD-PX820 recorder (call volume of $\sim 80 \mathrm{~dB}$ ). One call was pre-recorded at the site and another was copied from a collection recorded by Gibbon (2003). The location of this recording is unknown. The sampling rate was $44.10 \mathrm{kHz}$. To prevent possible habituation the exemplars were alternated between visits (Catchpole and Slater 2008). Each playback lasted $30 \mathrm{~s}$ and was conducted $100 \mathrm{~cm}$ above ground level; the flat microphone faced the direction in which the birds were located. Visibility (0-1 $\mathrm{m}$ above ground level) was limited to 5 to $40 \mathrm{~m}$ on either side of the foot path.

As a pilot study, on three occasions during playback interactions with guineafowl, their own alarm calls that were freshly recorded, were played back immediately twice (totalling six playbacks) and in all cases the birds also responded behaviorally as expected (described later) to their own calls. By also playing the two calls intended for this survey, similar responses were observed. These tests were conducted to ensure that the behavioral effects described in this paper were not peculiar to two calls only. During the pilot study the birds responded to the playback from a distance of $40 \mathrm{~m}$ and invariably approached the source. A measuring tape was used. The recorded playbacks were also used in the Hawaan Forest and similarly the birds responded with sound and approached the source.

The recording distances of the responding birds varied from 2 to $15 \mathrm{~m}$ (estimated). When the birds approached the playback device, they were not exposed to more than 
one sound playback (lasting $30 \mathrm{~s}$ ) and they were not exposed to the recordings or the researcher for more than $5 \mathrm{~min}$. Sounds were described as soft (40-60 dB) or loud $(>60 \mathrm{~dB}$ ) determined with a Lutron (SL-4013) sound level meter. Spectrograms of recordings were visualised to identify and eliminate background noise from bird sounds. Before and after playback, and during trips when playbacks were not conducted, the observer devoted $10 \mathrm{~min}$ on entering or leaving the forest to record any spontaneous guineafowl sounds. Interviews were conducted with the following people who worked in two forests on a regular basis during the past 10 years: P. Carnegie (tour guide), B. Njcamu (tour guide), D. Mguni (Ezemvelo KwaZulu-Natal Wildlife) and S. Ngcobo (security guard). The purposes of these interviews were mainly to estimate the number of flocks in the study area and the general sizes of the flocks during each visit and to compare this with the results of this current survey.

\section{Sound processing}

The calls were imported to Raven Pro 1.4, to create spectrograms for comparative analysis. The spectrogram settings were fixed at sample size $=256$, overlap $=50 \%$, grid spacing $=10.8$ and a $3 \mathrm{~dB}$ bandwidth of $25 \mathrm{~Hz}$. A Hamming-type window was used (Charif et al. 2010). The sound recording, behavior and spectrograms were assessed simultaneously (Erbe and King 2008). Selection boxes were drawn around syllables to conduct spectrogram measurements; "Frequency $5 \%$ " was used to determine low frequencies (it is the frequency that divides the selection into two frequency intervals $5 \%$ and $95 \%$ of the energy in the selection). "Frequency $95 \%$ " was used to determine high frequencies (it is the frequency that divides the selection into two frequency intervals $95 \%$ and $5 \%$ of the energy in the selection). Frequency bandwidth was the difference between the former and the latter measurement (Charif et al. 2010). The call rate of the different calls was equal to the average repetition of a syllable per second (Podos 1997). Figure 1 shows the spectrogram terminology used in this article.

\section{Results}

\section{Flocking behavior and flock sizes}

The mean flock size from November 2010 to December 2011 was $5.78(n=39$, range $=2-8, \mathrm{SD}=1.44)$ with an insignificant mean monthly flock size variation $\left(\chi^{2}=1.20\right.$, $\mathrm{df}=9, p=0.998)$. A larger flock of $\sim 30$ birds was observed in the adjacent Hawaan forest. Only one flock occupied the small forest during the past 10 years. During November 2011 the flock broke up into two smaller units of which one was a pair. The two sub-groups of the flock were observed in the forest apart from one another on five occasions ( $12.8 \%$ or 5 out of 39 observations). During pair-formation the female followed the male over a fairly large area (5 ha or more) and she was actively courtship-fed. She either took a piece of food from his beak or he pointed with his beak where she should peck. While this occurred, he stood close by, typically with his crop area protruding forward, but no sounds were audible. Importantly, no offspring were observed during this survey or during the previous five years [B. Njcamu (tour guide), D. Mguni (Ezemvelo KwaZulu-Natal Wildlife) and S. Ngcobo (security guard) personal communication].

\section{Calls}

The birds responded to both playback exemplars. The sounds of Crested Guineafowl were categorised into four sound groups:

Sound group 1: Alarm calls (Fig. 2) basically consisted of broad frequency bandwidth syllables manifested as clucks (Table 1). Alarm calls possessed the lowest frequencies of all calls (Table $1, \chi^{2}=433.22, \mathrm{df}_{1,3}, p<0.01$ ). These were generally loud calls which were produced by one or more members in the flock when the flock was

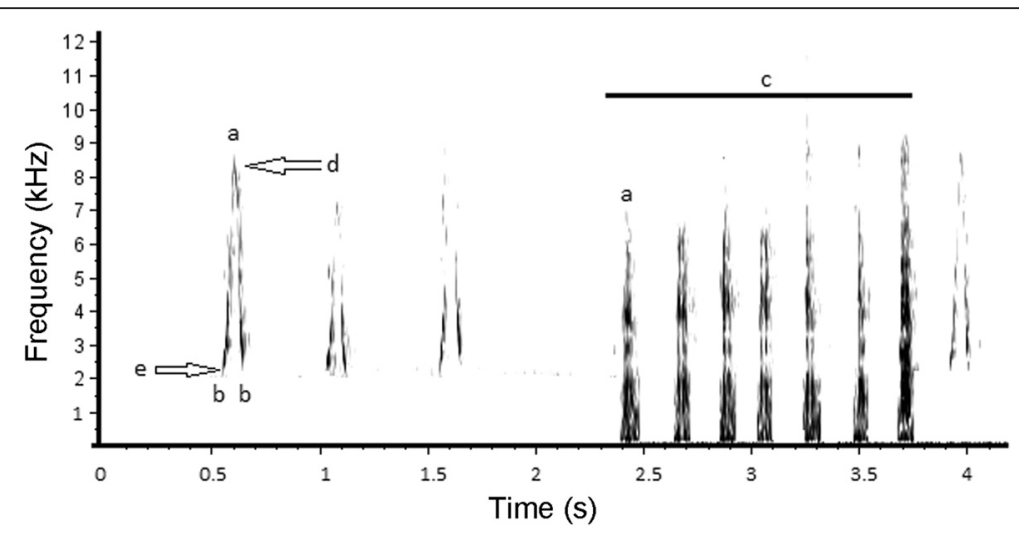

Fig. 1 Spectrogram showing the terminology used in the text: $a=$ single syllable; $b=$ two elements of the syllable; $c=$ phrase with syllables; $d$ (arrow) $=$ high frequency; e (arrow) = low frequency 


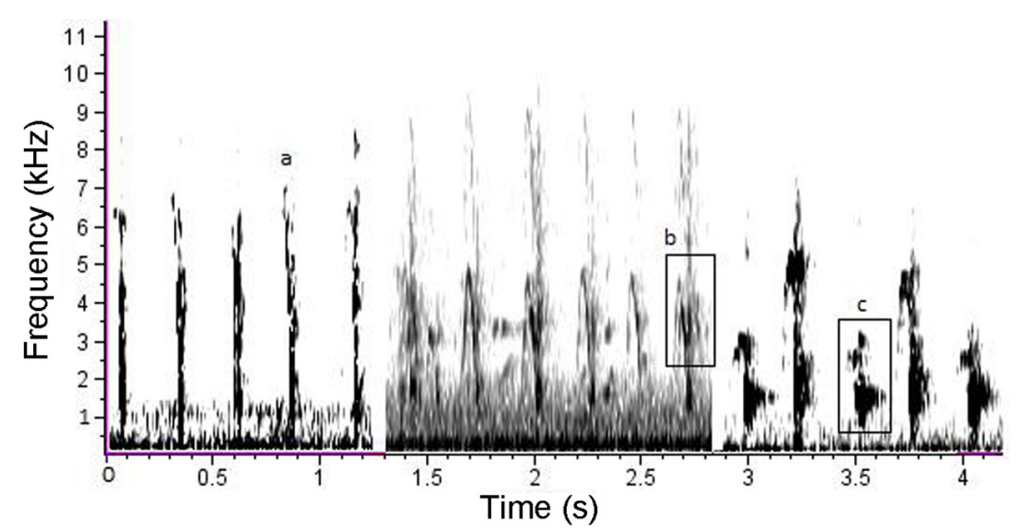

Fig. 2 Variation of the alarm calls of Crested Guineafowl: $a=$ the usual cluck; $b=$ the syllable with an element ( $\square$ ) attached to the front and; $c=$ alarm syllables interspersed with loose-standing tonal syllables ( $\square$ )

Table 1 Spectrogram measurements selected to compare the frequencies $(\mathrm{Hz})$ of basic syllables comprising the different calls of Crested Guineafowl

\begin{tabular}{|c|c|c|c|c|c|c|}
\hline & & Alarm call & Staccato & Tonal syllable & Tremolo & Twit \\
\hline \multirow[t]{5}{*}{ Frequency $95 \%$} & Number of exemplars ( $n)$ & 31 & 16 & 11 & 21 & 8 \\
\hline & Number of months sampled & 13 & 9 & 3 & 5 & 5 \\
\hline & Mean & 5965.79 & 7030.29 & 2411.53 & 5137 & 2584.68 \\
\hline & SD & 1062.62 & 1488.71 & 616.26 & 1404.8 & 134.86 \\
\hline & Range & $4306-8441$ & $4651-10335.9$ & $1722-3273$ & $3270-6718$ & $2411.7-2756$ \\
\hline \multirow[t]{5}{*}{ Frequency $5 \%$} & Number of exemplars ( $n)$ & 31 & 16 & 11 & 21 & 8 \\
\hline & Number of months sampled & 13 & 9 & 3 & 5 & 5 \\
\hline & Mean & 1077.8 & 2239.07 & 1988.6 & 2012.31 & 1614.85 \\
\hline & SD & 440.08 & 2775.48 & 2775.48 & 523.41 & 431.18 \\
\hline & Range & $172-1722$ & $1033-2411.9$ & $861-1032.6$ & $1894-2756$ & $861.3-2067.2$ \\
\hline \multirow[t]{5}{*}{ Frequency bandwidth } & Number of exemplars $(n)$ & 31 & 16 & 11 & 21 & 8 \\
\hline & Number of months sampled & 13 & 9 & 3 & 5 & 5 \\
\hline & Mean & 4942.81 & 5577.13 & 1268.36 & 3027.5 & 861 \\
\hline & SD & 1017.4 & 1348.64 & 703.24 & 1146.66 & 263 \\
\hline & Range & 4942.81-1017.49 & $5577.13-1348.64$ & $1268.36-703.24$ & $3027.5-1146.66$ & $516.8-1205.8$ \\
\hline \multirow[t]{5}{*}{ Rate (syllables /second) } & Number of exemplars $(n)$ & 10 & 21 & NA & 2 & 5 \\
\hline & Number of months sampled & 8 & 10 & NA & 2 & 4 \\
\hline & Mean & 1.33 & 22.81 & NA & 1.47 & 0.107 \\
\hline & SD & 0.79 & 7.68 & NA & 0.38 & 0.034 \\
\hline & Range & $0.21-2.8$ & $8-2.5$ & NA & $1.2-1.75$ & $0.064-0.142$ \\
\hline \multirow[t]{5}{*}{ Phrase size (syllables/bout) } & Number of exemplars $(n)$ & 23 & 18 & 11 & 1 & 8 \\
\hline & Number of months sampled & 5 & 10 & 3 & 5 & 5 \\
\hline & Mean & 6.18 & 8.35 & 1 & 1 & 1 \\
\hline & $S D$ & 4.15 & 2.6 & 0 & 0 & 0 \\
\hline & Range & $2-17$ & $6-13$ & 0 & 0 & 0 \\
\hline
\end{tabular}

Not assessed (NA) = rate of tonal syllables was intermittent; Frequency $95 \%$ (the frequency that divides the selection into two frequency intervals $95 \%$ and $5 \%$ of the energy in the selection); Frequency $5 \%$ (the frequency that divides the selection into two frequency intervals $5 \%$ and $95 \%$ of the energy in the selection). Frequency bandwidth is the difference between Frequency $95 \%$ and Frequency $5 \%$. Phrase size = syllables in a bout 
confronted by an intruder such as a human ( $n=23$ flocks). The purpose was to alert one another, seen by their upright postures in response to the call $(n=10)$. When one or two guineafowl (or two subgroups) were separated by 5 to $10 \mathrm{~m}$ due to an intruder (human), both groups used the alarm calls antiphonally $(n=5)$ to keep contact and to determine one another's position in dense vegetation. They kept their heads high and the two sub-groups would look in the direction of one another during this antiphonal calling. On my approach during playbacks the flock sometimes mobbed by standing side by side while clucking as if to confront the me (intruder) head-on $(n=5)$. On four occasions the mobbing birds were split into two subgroups, with one group of two birds 5 to $10 \mathrm{~m}$ from the larger flock. Under these conditions a dominant bird invariably stood on an elevation (e.g. a dry $\log )(n=3)$, arching its neck and head forward and calling repeatedly to reveal its position to other group members.

There were at least four variations of the alarm call: (1) the phrase consisted mostly of a repetition of syllables $(n=12)$ (Fig. 2a); (2) the syllable often started with a tonal element $(n=3)$ (Fig. 1b); (3) some syllables had a strong nasal quality (similar to Fig. 2a) $(n=5)$ and (4) alarm syllables were sometimes interspersed with loosestanding tonal syllables (Fig. 2c) $(n=3)$. The phrases containing the (calm notes) tonal element/syllable invariably followed an initial spell of frantic alarm calls.

Sound group 2: Staccato calls (Fig. 3) were loud, rapidly produced syllables (Table 1 ). These possessed the broadest frequency bandwidth $\left(\chi^{2}=3087.13, \mathrm{df}_{1,3}, p<0.01\right)$ and the highest frequency $\left(\chi^{2}=2278.16, \mathrm{df}_{1,3}, p<0.01\right)$ compared with all other calls (Table 1 ). On occasions when the birds were suddenly confronted by humans $(n=5)$ and in one case by a Martial Eagle (Polemaetus bellicosus)

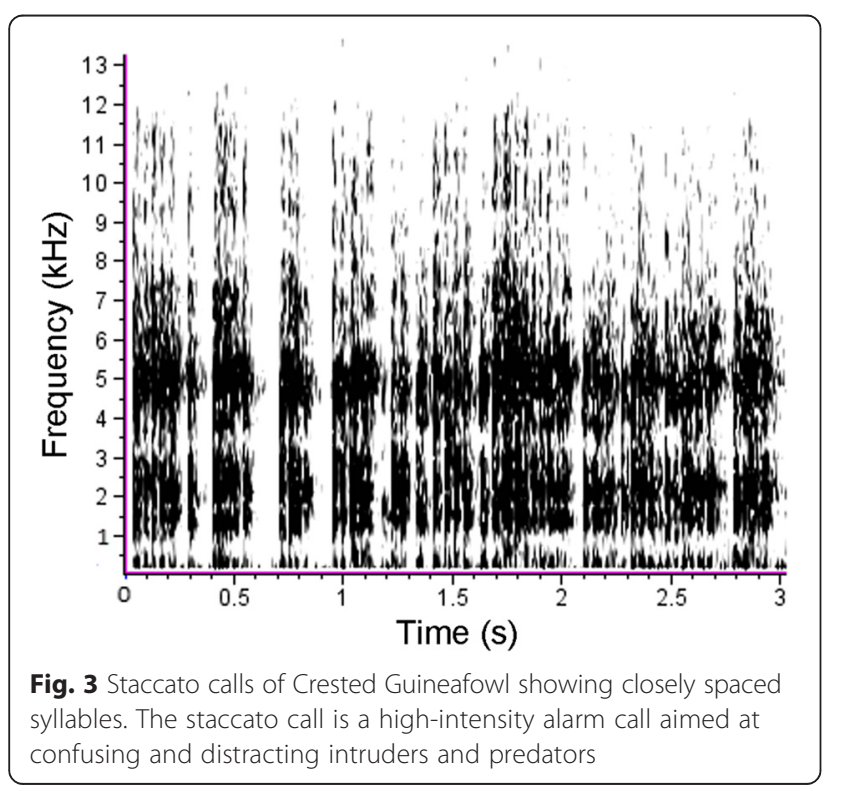

(P. Carnegie, personal communication), the flock split up into two or three smaller groups and ran short distances $(5-10 \mathrm{~m})$ in different directions, coming to a halt while maintaining the call. However, in no instance did the guineafowl run away from the intruder in order to escape it; this strategy was instead employed to digress the intruder's attention to a number of groups.

Sound group 3: Rhythmic calls (Fig. 4) were basically a combination of the syllables explained in Table 1, consisting of alarm syllables, staccato and tonal sounds. These calls were produced by guineafowl after a spell of alarm or staccato calls following a confrontation, and was uttered as the group was uniting $(n=4)$.

Sound group 4: Tremolos and twits (Fig. 5) were single-syllabled calls which consisted of tonal sounds (without harmonics) with narrow frequency bandwidths, and did not possess particularly high or low frequencies compared with all other calls (Table 1). Tremolos and twits are soft contact calls produced by more than one flock member as the birds foraged quietly across the forest floor, scratching in the leaf litter $(n=20)$. Twits were also evoked by strange noises (e.g. clicking of a camera) or oncoming humans $(n=2)$, and served as an early warning signal for members at close range.

\section{Responses to playbacks}

Generally speaking, when Crested Guineafowl were relatively far away (say $20 \mathrm{~m}$ ) from humans and not interpreting the presence of humans as intruding (such as a sudden encounter at close range), they were heard producing soft tremolo contacts sounds. Calls were never heard on the perimeter of the forest (out in the open). The footpath was traversed on 142 occasions (71 times in one direction and 71 times back) and the guineafowl flock was visually located on 39 occasions (27.46 \%). Playbacks were conducted during 20 of these visual encounters; the birds responded 19 (95\%) times with callbacks, and all the members of the flock emerged and became visible. This made it possible to count all the birds. During six of the occasions on which guineafowl were called up with playbacks, they were again observed on return, after 10 to $15 \mathrm{~min}$, foraging about 20 to $30 \mathrm{~m}$ from where they were initially located, and producing soft tremolo sounds.

The mean group size (mean $=6.55$, range $=4-7, \mathrm{SD}=0.9$, $n=19)$ of Crested Guineafowl counted following playback was significantly larger than the mean group size of Crested Guineafowl counted when playback was not used (mean = 5.25 , range $=2-7, \mathrm{SD}=1.68, n=20$ ) (ANOVA: $F=8.52$, $\mathrm{df}_{1,36}, p=0.006$ ). Blind calling, when no guineafowl were observed, was done on 30 occasions during a 6-month period. On these occasions, vocal responses were elicited three times (10\%), and the flock revealed itself and could be counted. 


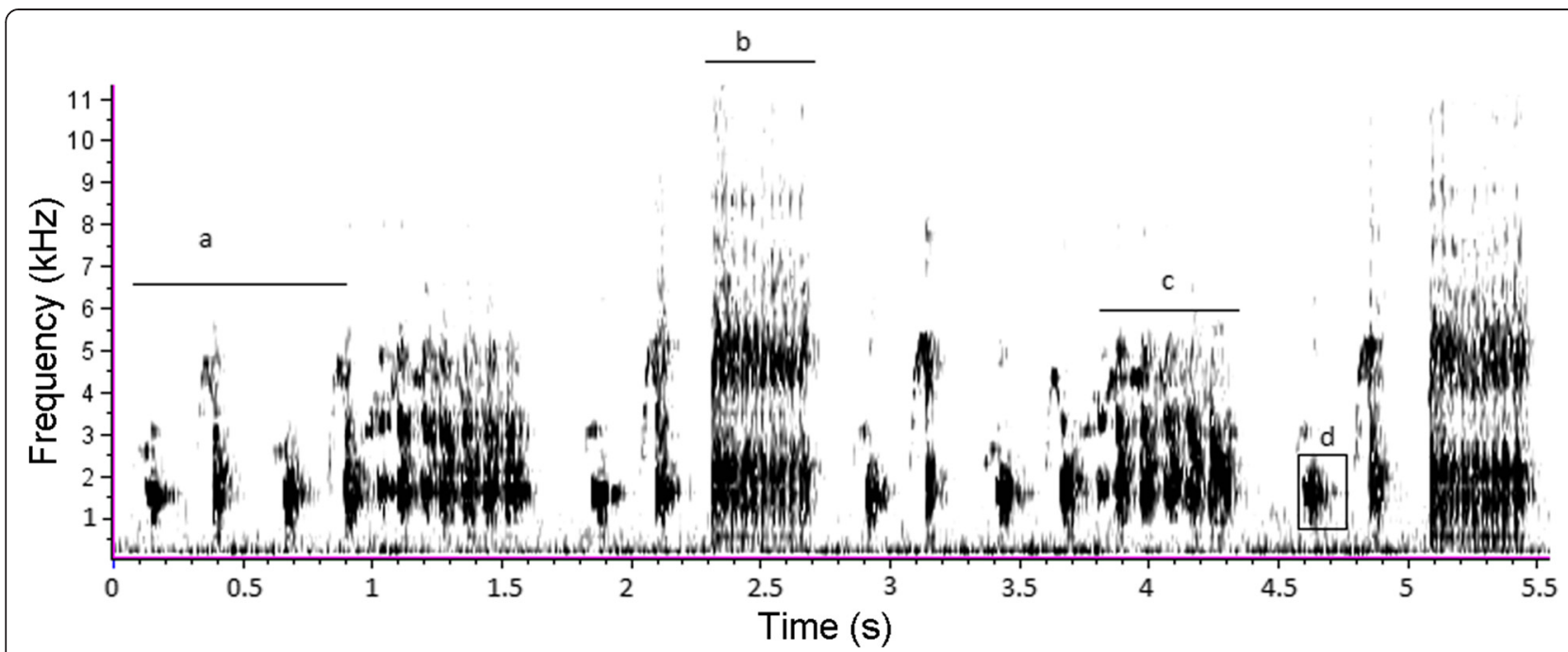

Fig. 4 Complex rhythmic diversion/disrupting call of Crested Guineafowl: $a=$ clear syllables with tonal elements; $b=$ rapid syllables (staccato sound); $c=$ rapid tonal syllables (note broader syllables); $d=$ tonal syllables which are broader and lower in frequency. This call creates a ventriloquist effect in the forest

\section{Audibility}

The replication of four guineafowl alarm calls, (mean; $\sim 80.25$ $\mathrm{kHz}$ at source), were audible to one human up to 50-60 m from the source (recorder) in the forest. At a distance of $50 \mathrm{~m}$ the $\mathrm{dB}$ of the calls were $<45 \mathrm{~dB}$ and not traceable on spectrographs.

\section{Discussion and conclusions \\ Quiet habits}

Crested Guineafowl lived a relatively quiet flock life and mostly made contact sounds only. There is some evidence to suggest that Crested Guineafowl calls were not audible further than 50-60 m from the source, and they were certainly never heard on the perimeter of the forest. This is unlike galliform species in grasslands, such as Orange River Francolins (Scleroptila levaillantoides), which make territorial calls, and Helmeted Guineafowl females, which make repeated "buckwheat" calls during summer: both are often heard over distances of 100 to 120 m (van Niekerk 2010a; JH van Niekerk unpublished). Predators would be able to approach much closer in forests, and such close encounters leave little room for escape. Living in flocks in dense vegetation could be a physical handicap for large birds such as Crested Guineafowl, and so a silent lifestyle probably compensates for this disadvantage.

\section{Repertoire size}

Eight Crested Guineafowl calls were described. However, since no offspring were present, it is expected that this repertoire size would be larger. Furthermore, a close-up survey, such as the one done on Helmeted Guineafowl in captivity (Maier 1982) may well reveal finer variations within the four sound groups (Table 1). African galliforms

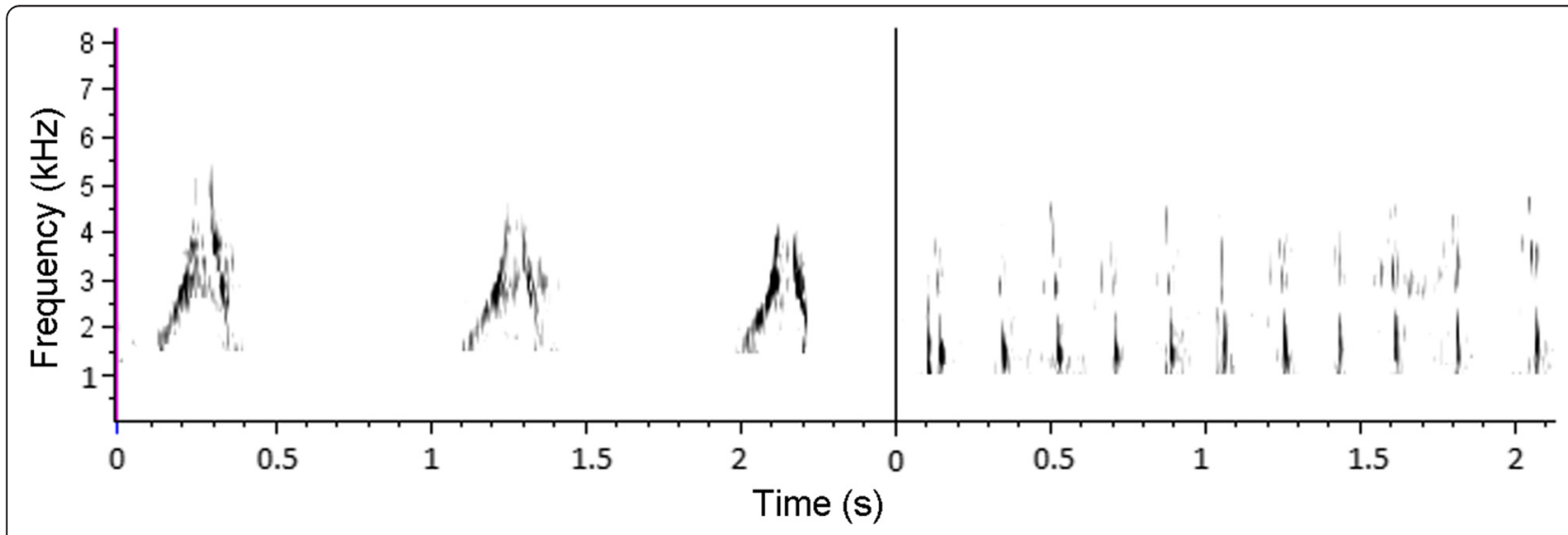

Fig. 5 Tremolos (left panel) and twits (right panel) of Crested Guineafowl 
have small repertoires. Eight or nine calls were reported for Crested Guineafowl, while six were reported for Orange River Francolin (van Niekerk 2012), seven for Crested Francolin (Ortygornis sephaena) (van Niekerk 2010b), four calls for Coqui Francolin (Peliperdix coqui) (JH van Niekerk unpublished) and six to eight for Spurfowls Pternistis spp. (Madge and McGowan 2002; van Niekerk 2013). However, the variation in the alarm call of Crested Guineafowl was not found in the alarm calls of spurfowls or francolins. The calm tonal calls between the alarm clucks of Crested Guineafowl were possibly "acknowledgement calls" by members in response to the signalling calls from other flock members. This appears to be a trait of highly sociable galliforms that was absent among francolins and spurfowls, which mostly live singly or in family groups for part of the year.

\section{Adaptive nature of calls}

The alarm call of Crested Guineafowl possessed the lowest frequency of all the calls (Table 1). This is regarded as an adaptation, since low frequencies with longer wavelengths propagate better than high frequencies through forests (Catchpole and Slater 2008). Since this is a warning call, or a call that keeps members in contact with one another, it is indeed expected that this call will travel relatively unattenuated and reach the recipients as a clear signal.

When staccato calls were produced by Crested Guineafowl the threat of an intruder (e.g. attack by an eagle) was more intense than in the case of alarm calls (Fig. 3), as they comprised rapidly produced syllables which probably exacerbated intruder confusion (Kroodsma and Miller 1982; Slabbekoorn et al. 2002). The high frequencies of staccato calls were possibly produced to confuse nearby intruders, since these frequencies bounce off objects such as tree bark and leaves, making it difficult to identify the location of the calling guineafowl in dense vegetation (Catchpole and Slater 2008). However, these high frequencies might also be used as a cue by conspecifics to assess the distance between separated birds in dense vegetation.

The purpose of the Crested Guineafowl's rhythmic call (Fig. 4) was to bring together dispersed members separated by a distance of about 5 to $10 \mathrm{~m}$. It may also be a duet between flock members, but this possibility requires further study. The purpose of the tremolo and twit calls was to keep the flock together as a close-knit group during foraging. These soft calls were inwardly orientated towards members in the flock. Therefore, it was expected that high or low frequencies to gauge distance or to reach isolated birds would not be part of the acoustic properties of contact calls (Table 1, Fig. 5).

\section{Comparison with Helmeted Guineafowl}

The calls of Crested and Helmeted Guineafowl are structurally and functionally similar (Maier 1982). Helmeted
Guineafowl also utter (1) a single-syllabled alarm cluck similar to Fig. 2 (also see Little and Crowe 2011); (2) a staccato call when they are confronted by predators (similar to Fig. 3); (3) tremolos, which are narrow frequency bandwidth contact calls (similar to Fig. 5); and (4) soft twit syllables with narrow frequency bandwidth which are responses to strange noises (e.g. the clicking of a camera) similar to Fig. 5. Importantly, detailed studies are required to compare the frequencies, rate and strophe lengths of calls uttered by both species as these are expected to differ given the respective habitats of these birds. Helmeted Guineafowl live in savannah bushveld and open grasslands.

The "buckwheat" iambus call emitted by Helmeted Guineafowl females was absent in Crested Guineafowl; conversely, the complex rhythmic diversion call sound of Crested Guineafowl (Fig. 4) is absent in Helmeted Guineafowl. Iambus calls by Helmeted Guineafowl females are loud and travel quite far. A call of this nature in the Crested Guineafowls' repertoire would be counterproductive to their secretive lifestyle. On the other hand, the rhythmic call of Crested Guineafowl is probably unnecessary for Helmeted Guineafowl, which lives out in the open, since the birds readily have more visual contact in order to re-unite after being dispersed by a predator.

\section{Conservation}

Traditionally, the usefulness of playbacks for counting birds was dependent on the variation in response rate by members of a population. Some birds may not respond to playbacks for various reasons such as habituation and lead to inaccurate estimates from season to season (Gregory et al. 2004). Conversely, the high response rate and the fact that Crested Guineafowl approach the source in flocks, makes playbacks a reliable tool to count and determine the flock size trends in isolated forests without the intervention of trapping and marking (Lawes et al. 2006). More specifically, playbacks (alarm calls) can be used to locate and count Crested Guineafowl at point transects or along a continuous transect in dense forests where clearings are often limited to narrow roads or paths (Sutherland et al. 2004; Ward and Schlossberg 2004; Mota and Depraz 2004). However, a call of $\sim 80 \mathrm{~dB}$ probably did not elicit any response beyond $60 \mathrm{~m}$, owing to the attenuation of sound in dense forests; this could explain the fact that only $10 \%$ of all blind calls elicited responses from the flock. The implication is that to search for Crested Guineafowl, one would have to do playbacks at about $50 \mathrm{~m}$ intervals in any direction in the forest to cover all possible guineafowl. Conveniently, unlike other birds such as the Red-crested Korhaan (van Niekerk 2014), during the survey it was not just a male that responded, but normally a dominant male with the rest of the flock calling and 
joining the dominant bird, as a result of which they were all visible for counting.

Playback had no apparent negative effect on the group cohesion or presence of guineafowl. The birds responded to playbacks every month with the exception of a single occasion. In fact, on six occasions the birds were called up with playbacks and when the observer returned along the same transect 10 to 15 min later, the birds were still foraging in one group in the same general area, about 20 to $30 \mathrm{~m}$ from where they were initially located. A 30second playback to Crested Guineafowl can be safely conducted to visually locate birds one day per month. No guineafowl should be exposed to repeated playbacks and the observer for more than $5 \mathrm{~min}$. This will prevent the habituation that was found in the case of the Orange River Francolin, where playbacks were conducted weekly (cf. van Niekerk 2012). Calls are often amplified to elicit responses from birds but care must be taken not to disturb breeding activity (Kroodsma and Miller 1982; Sutherland et al. 2004; Lawes et al. 2006). The protocol followed in this survey must be seen as baseline but more regular playbacks may also be non-intrusive. Finally, more tests are required especially since this study did not cover any breeding activities or when offspring were present.

\section{Competing interest}

The author declares that he has no competing interest.

\section{Acknowledgement}

I thank Ann Elizabeth Jones for assistance during field work.

Received: 8 December 2014 Accepted: 26 May 2015

Published online: 21 July 2015

\section{References}

Brandes TS (2008) Automated sound recording and analysis techniques for bird surveys and conservation. Bird Conserv Int 2008:S163-s173

Catchpole CK, Slater PJB (2008) Bird song: biological themes and variations. Cambridge University Press, Cambridge

Charif RA, Waack AM, Strickman LM (2010) Raven Pro 1.4 user's manual. Cornell Lab of Ornithology, Ithaca, NY

Crowe TM (1978) The evolution of guineafowl (Galliformes, Phasianidae, Numidinae): taxonomy, phylogeny, speciation and biogeography. Ann S Afr Mus 76:43-136

Crowe TM (1979) Adaptive morphological variation in Helmeted Guineafowl Numida meleagris and Crested Guineafowl Guttera pucheranii. Ibis 121:313-320

Erbe C, King AR (2008) Automatic detection of marine mammals using information entropy. J Acoust Soc Am 124:2833-2840

Gibbon G (2003) Southern African bird sounds. Southern African Birding cc, Westville

Gregory RD, Gibbons DW, Donald PF (2004) Bird census and survey techniques. In: Sutherland WJ, Newton I, Green R (eds) Bird ecology and conservation: a handbook of techniques. Oxford University Press, Oxford

Harris JBC, HASKELL DG (2013) Simulated birdwatchers' playback affects the bahavior of two tropical birds. PLOS ONE 8:e77902

Hill G (1974) Observations on a relationship between Crested Guineafowl and Vervet Monkeys. Bull Br Ornith C 94:68-69

Kroodsma DE, Miller EH (1982) Acoustic communication in birds, vol 1. Production. Academic Press, New York, Perception and Design Features of Sounds

Lawes MJ, Fly S, Piper SE (2006) Gamebird vulnerability to forest fragmentation: patch occupancy of the Crested Guineafowl (Guttera edouardi) in Afromontane forests. Anim Conserv 9:67-74

Lima AMX, Roper JJ (2009) The use of playbacks can influence encounters with birds: an experiment. Revista Brasileira de Ornitologia 17:37-40
Little R, CROWE TM (2011) Gamebirds of southern Africa. Struik, Cape Town Madge S, Mcgowan P (2002) Pheasants. Partridges and Grouse, Christopher Helm, London

Maier V (1982) Acoustic communication in the Guinea Fowl (Numida meleagris): structure and use of vocalizations, and the principles of message coding. Zeitschrift fur Tierpsycholgie 59:29-83

Mota PG, Depraz V (2004) A test of the effect of male song on female nesting behavior in the serin (Serinus serinus): a field playback experiment. Ethology 110:841-850

Mucina L, Rutherford MC (eds) (2006) The vegetation of south Africa, Lesotho and Swaziland, Strelizia 19. South African National Biodiversity Institute, Pretoria

Podos J (1997) A performance constraint on the evolution of trilled vocalizations in a songbird family (Passeriformes: Emberizidae). Evolution 52:537-551

Rasaru R (2007) Managing coastal development in rapidly developing areas: the case of Umhlanga Rocks. Master's Degree Dissertation, University of KwaZulu-Natal, p 166

Slabbekoorn H, Ellers J, Smith TB (2002) Birdsong and sound transmission: the benefits of reverberations. Condor 104:564-573

Sutherland WJ, Newton I, Green R (2004) Bird ecology and conservation: a handbook of techniques. Oxford University Press, Oxford

van Niekerk JH (2010a) Social organization of a flock of Helmeted Guineafowl (Numida meleagris) at the Krugersdorp Game Reserve, South Africa. Chinese Birds 1:22-29

van Niekerk JH (2010b) Vocal behaviour of Crested Francolin Dendroperdix sephaena in response to playback calls. Ostrich 81:149-154

van Niekerk JH (2012) Vocal behaviour of Orange River Francolin Scleroptila levaillantoides based on visual and sound playback surveys. Ostrich 83:147-152

van Niekerk JH (2013) Vocal structure, behavior and partitioning of all 23 Pternistis spp. into homologous sound (and monophyletic) groups. Chinese Birds 4:210-231

van Niekerk JH (2014) Vocal behaviour of the Red-crested Korhaan, Lophotis ruficrista, in South Africa. S Afr J Wildl Res 44:24-31

Ward MP, Schlossberg S (2004) Conspecific attraction and the conservation of territorial songbirds. Conserv Biol 18:519-525

Wilson KJ (1965) A note on the crop contents of two Crested Guineafowl Guttera edouardi (Hartlaub). Ostrich 36:103-106

\section{Submit your next manuscript to BioMed Central and take full advantage of:}

- Convenient online submission

- Thorough peer review

- No space constraints or color figure charges

- Immediate publication on acceptance

- Inclusion in PubMed, CAS, Scopus and Google Scholar

- Research which is freely available for redistribution 